\title{
SUBMERGED AND IMPACTED DECIDUOUS MOLARS IN 27-YEAR-OLD MALE PATIENT - A CASE REPORT
}

\author{
Al Hassan Ali Owis ${ }^{1}$,Zarah Ahmed Dahas², Omar Dharaj3, Turki Abduh Khurayzi ${ }^{4}$, Fareedi Mukram Ali ${ }^{5}$
}

${ }^{1}$ Dental Intern, College of Dentistry, Jazan, Kingdom of Saudi Arabia.

${ }^{2}$ Dental Intern, College of Dentistry, Jazan, Kingdom of Saudi Arabia.

${ }^{3}$ Dental Intern, College of Dentistry, Jazan, Kingdom of Saudi Arabia.

${ }^{4} 6^{\text {th }}$ Year Dental Student, College of Dentistry, Jazan, Kingdom of Saudi Arabia.

${ }^{5}$ Assistant Professor, Department of Oral and Maxillofacial Surgery, College of Dentistry, Jazan, Kingdom of Saudi Arabia.

HOW TO CITE THIS ARTICLE: Owis AHA, Dahas ZA, Dharaj O, et al. Submerged and impacted deciduous molars in 27-year-old male patient- a case report. J. Evolution Med. Dent. Sci. 2019;8(30):2434-2435, DOI: 10.14260/jemds/2019/532

\section{BACKGROUND}

Deciduous molar should naturally exfoliate when roughly three-fourths of the root of the replacing premolar has formed. When a deciduous molar continues beyond this point, it is measured as over-retained.1,2 The impaction of tooth may be primary, where the teeth had never been erupted (also called primary failure of eruption) or it may be secondary, where the teeth after eruption becomes impacted again due to several factors. The failure of eruption is primarily diagnosed when the tooth which is unerupted is covered by an intact mucosa and radiographs disclose the tooth to be totally covered in the jaw bone. ${ }^{3}$ The prevalence of submerging of deciduous molars is reported to be in the range of $1.3-8.9 \%$. The prevalence is in peak at the age of eight-to-nine-years, with an incidence rate higher among siblings. ${ }^{1,4}$

In the present article, we present a case of two submerged deciduous molar teeth and one impacted deciduous molar tooth in a 27-year-old male patient.

Submerged tooth is present as below the occlusal plane level. Ankylosis of the tooth is considered to be a chief reason for submergence. Deciduous teeth which are submerged have the potential to result in malocclusion by causing hindrance of their exfoliation and consequent substitution by permanent teeth. Also lead to malocclusion resulting in extrusion of opposing tooth and tilting of proximal teeth. Impaction of the deciduous molar is less common than the impaction of the permanent tooth. In this case report presented a case of two submerged deciduous molar teeth and one impacted deciduous molar tooth in 27-year-old male patient.

\section{PRESENTATION OF CASE}

A 27-year-old male patient came with a complaint of missing teeth and over retained teeth in the mandibular right and left side and also in the maxillary left side. On clinical examination, permanent maxillary $2^{\text {nd }}$ premolar of left side was missing (Fig. 1).

'Financial or Other Competing Interest': None.

Submission 20-05-2019, Peer Review 08-07-2019,

Acceptance 15-07-2019, Published 29-07-2019.

Corresponding Author:

Dr. Fareedi Mukram Ali,

Assistant Professor,

Department of Oral and Maxillofacial Surgery,

College of Dentistry, Jazan,

Kingdom of Saudi Arabia.

E-mail:faridi17@rediffmail.com

DOI: $10.14260 /$ jemds/2019/532

\section{(c) (i) $(\Theta$}

In the mandibular arch, permanent mandibular $2^{\text {nd }}$ premolar of right and left side were missing. Also, in the mandibular arch, deciduous mandibular second molar of both right and left side were found to be over retained and infraoccluded (Fig. 2). Radiographical examination using Orthopantomograph (Fig. 3) had shown presence of submerged right and left side deciduous second molars. No periodontal space was visible around the roots of the submerged tooth on left side, whereas on the right side the roots were not clearly visible. These finding will suggest that the teeth were ankylosed in the alveolar sockets. The over retained deciduous molars were infra-occluded. The surrounding teeth were tilted in the space. In the maxillary left side quadrant, deciduous second molar was seen impacted in the maxillary bone. A clear width of bone was visible on the occlusal part of the tooth, suggesting the presence of impacted deciduous maxillary second molar on the left side.

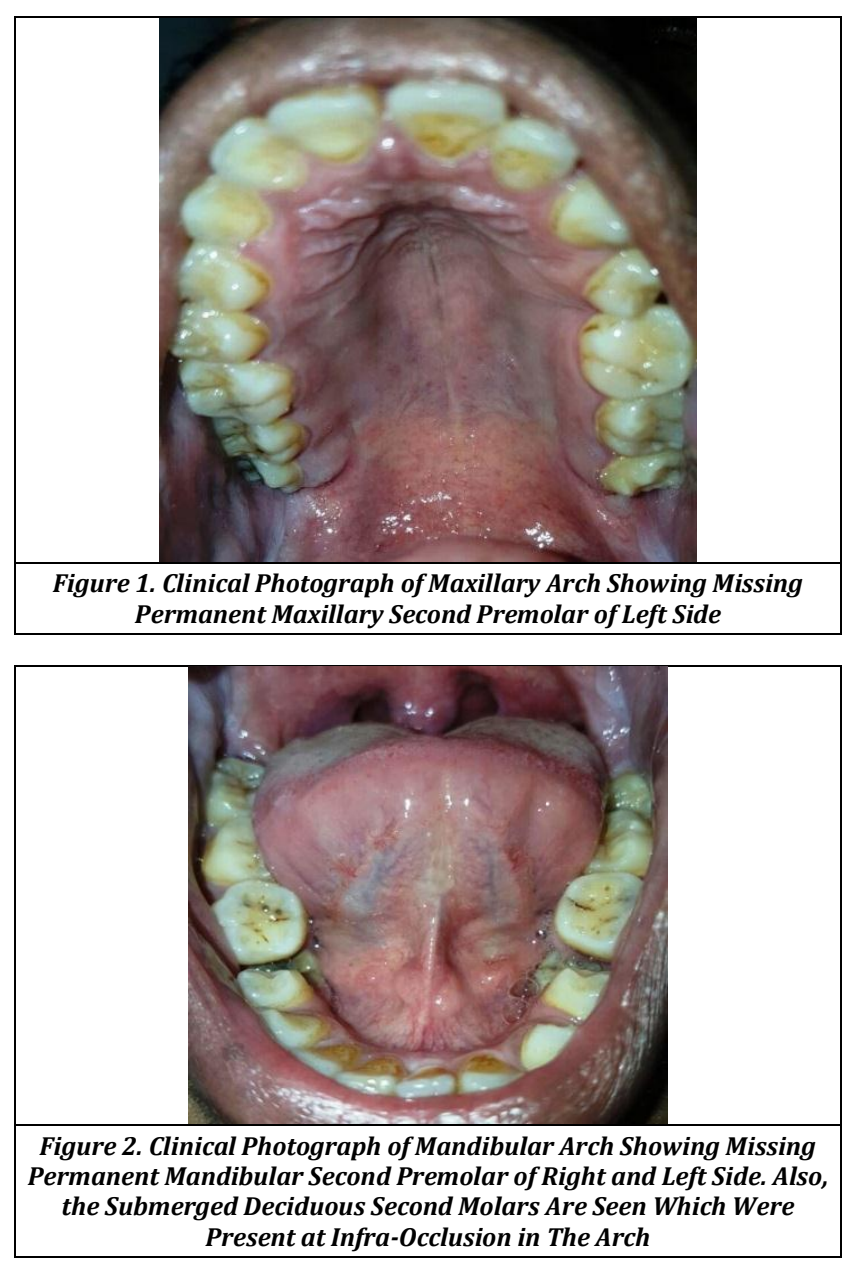




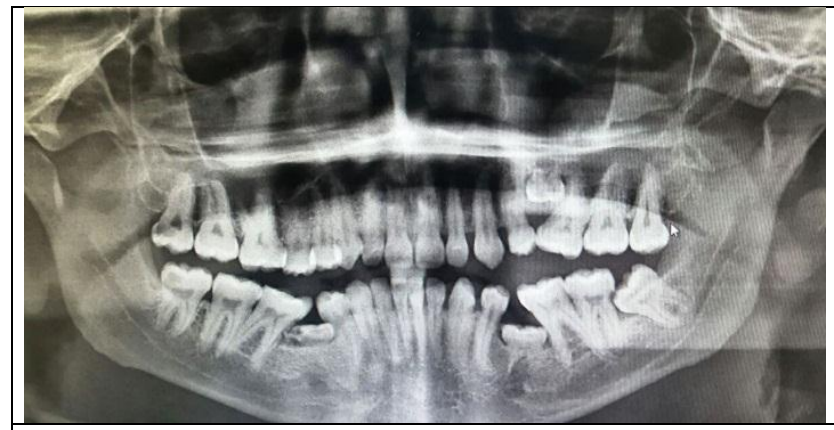

Figure 3. Radiographic Examination of The Patient Showing Presence of Impacted Maxillary Second Deciduous Molar and Over Retained Deciduous Mandibular Second Molars of Right and Left Side

\section{DISCUSSION}

The mandibular $1^{\text {st }}$ primary molars are the most commonly affected teeth, followed by primary second maxillary and mandibular molars. ${ }^{5}$ In the present case deciduous mandibular second molars were found submerged and in infra-occlusion.

In case of ankylosis of the tooth, loss of the periodontal ligament space is seen in radiographs, the roots are of lesser radio-opacity, and as the ankylosis increases, they are less distinguished from the surrounding bone.5,6

In general, mandibular deciduous molars are affected more than 10 times than maxillary deciduous molar. ${ }^{3}$ In the present case, the deciduous maxillary second molar was found impacted in the jaw bone.

The incidence of missing teeth varies as the study population changes, but several investigations have found that after third molars, the second premolar is the most frequent congenitally missing tooth. ${ }^{1}$

The occurrence of submerged primary teeth can cause difficulties in eruption and development of the permanent dentition, and it may lead to harms on function, occlusion, and aesthetics. When the exfoliation of ankylosed teeth is late, problems like deviated eruption paths for nearby and opposing teeth, delayed eruption of succedaneous permanent teeth and also the position of the tooth germ can be affected leading to hooked roots. ${ }^{2,7}$

For the management of patient with submerged teeth, the conservative treatment option was composite build-up or a stainless-steel crown to prevent tipping of adjacent teeth and to bring back the occlusion to the position, thus prevents opposing arch tooth from supra-eruption. However, because the infra-occlusion was severe in this case, it is not possible to build-up of the occlusal table with composite resin or stainless-steel crown. ${ }^{5}$
As recommended by many authors, extraction is an eventual treatment. Extraction in early stage is only suitable whenever there is occlusal trouble with severe tipping of teeth and malalignment of the permanent succedaneous tooth combined with severe infra-occlusion. However, early extraction is technically more difficult, as it can result in root fractures or disturbance of the successor permanent tooth bud. ${ }^{5}$

\section{CONCLUSIONS}

Although the more commonly ankylosed teeth with permanent successors exfoliate usually, proper and early intervention for the prevention of occlusal discrepancies is advisable. When the permanent successors are absent as in the present case, multidisciplinary approach with the consideration of all the parameters is advisable.

\section{REFERENCES}

[1] Sabri R. Management of over-retained mandibular deciduous second molars with and without permanent successors. World J Orthod 2008;9(3):209-20.

[2] Matsuyama J, Kinoshita-Kawano S, Hayashi-Sakai S, et al. Severe impaction of the primary mandibular second molar accompanied by displacement of the permanent second premolar. Article ID 582462, Case Reports in Dentistry 2015;2015:1-5.

[3] Hashim HA, Al-Qahtani AA, Taha SM, et al. Management of complete impacted maxillary second deciduous molar with the aid of cone-beam computed tomography: case report and a review of the literature. J Orthod Sci 2013;2(4):130-5.

[4] McGeown M, O'Connell A. Management of primary molar infraocclusion in general practice. J Ir Dent Assoc 2014;60(4):192-8.

[5] Parisay I, Kebriaei F, Varkesh B, et al. Management of a severely submerged primary molar: a case report. Article ID 796242, Case Reports in Dentistry 2013;2013:1-4.

[6] Mishra SK, Jindal MK, Singh RP, et al. Submerged and impacted primary molars. International Journal of Clinical Pediatric Dentistry 2010;3(3):211-3.

[7] Cappellette M, Gonçalves RM, Yuki AKA, et al. Diagnosis and treatment planning for primary molar Ankylosis along with un-erupted maxillary premolar: case report. Journal of Surgery 2017;13(2):67-75. 